\title{
OS ALVOS DA CHECAGEM: UMA ANÁLISE SOBRE A COBERTURA DE FACT-CHECKING NAS ELEIÇÕES DE 2018
}

\author{
Paulo Ferracioli ${ }^{1}$
}

\begin{abstract}
Resumo
Os sites de fact-checking (agentes jornalísticos dedicados exclusivamente a confirmar a veracidade de alegações e notícias) têm crescido pelo mundo e, no Brasil, o projeto Comprova operou ao longo das eleições de 2018 exclusivamente com esse fim. Tendo em vista que os alvos das checagens eram os candidatos à presidência, o objetivo do presente artigo é comparar se a visão dos jornalistas sobre a escolha dos checados ao longo da produção coincidiu com a recorrência de checagens postadas. A pesquisa se baseou em duas estratégias metodológicas complementares. Foram efetuadas entrevistas semi-estruturadas com uma amostra de quatro jornalistas que atuaram no projeto Comprova. Também foi feita uma análise de conteúdo de todos os posts publicados pelo site, com focos nas seguintes categorias: o candidato citado no conteúdo checado e a valência do conteúdo em relação ao postulante. A análise de conteúdo demonstrou que o político mais citado foi Jair Bolsonaro (43,4\% dos textos), com o dobro de citações que Fernando Haddad (23,4\%). Houve uma distinção bem clara quanto ao conteúdo desmitificado: enquanto $88,2 \%$ dos posts que mencionavam o candidato do PT versavam sobre aspectos negativos de Haddad, 54\% das notícias verificadas pelo Comprova sobre PLS checavam conteúdo positivo a Bolsonaro. Essa tendência também foi percebida pelos jornalistas, que reconheceram que sua atuação sobre os dois candidatos foi maior e apontaram que o modo de realização da campanha de Bolsonaro acarretou essa discrepância de conteúdos mais benéficos a ele. A predominância dos textos benéficos a Bolsonaro e prejudiciais a Haddad, aliada à percepção dos jornalistas de que esse conteúdo era mais recorrente, comprova que a esfera digital foi uma das principais áreas da estratégia de comunicação do Bolsonaro no pleito. Futuras pesquisas podem investigar o modo de circulação dessas notícias falsas, tanto durante as eleições quanto após a posse.
\end{abstract}

Palavras-Chave: Fact-checking ; Eleições; Jornalismo político.

\section{INTRODUÇÃO}

A expressão fake news parece já ter ganho o debate público. Nas eleições de 2018, houve críticas de candidatos sobre terem sido espalhadas informações falsas que afetaram a formação de

\footnotetext{
1 Doutorando no Programa de Pós-Graduação em Ciência Política da UFPR. ferracioli.paulo@gmail.com,
} http://orcid.org/0000-0001-9355-3365. 
opinião do eleitor. Não só no âmbito político essas desinformação é impactante: a eclosão do novo coronavírus foi acompanhada pela disseminação em larga escalas de informações que não eram cientificamente comprovadas. As discussões sobre a possível regulamentação chegaram até mesmo ao Congresso Nacional, onde um projeto de lei que tenta coibir essa prática nociva está em debate, mas o curto tempo para discussão e as ambiguidades do texto tem levado a críticas de setores como pesquisadores acadêmicos e as empresas de tecnologia.

O ambiente digital é propício para facilitar essa disseminação de informações, por meio da utilização em larga escala das redes sociais digitais. Nessas plataformas, já foi apontado que é mais provável que as pessoas acreditem naquilo que foi postado por seus amigos e conhecidos, o que pode levar a redutos de pensamento similar e, às vezes, incorreto (MENG; JUN; JOHAR, 2017).

Como uma das estratégias para combater a desinformação por meio das redes sociais, temse fortalecido os agentes de checagens de fatos, que se fortaleceram na última decada para combater esses conteúdos, embora já existissem antes (KUŚ; BARCZYSZYN-MADZIARZ, 2020). Incentivada até mesmo pelas próprias redes sociais, esses agentes apontam o que é verdadeiro, falso, impreciso, exagerado, entre outros rótulos.

Por ser um produto jornalístico, a checagem de fatos está sujeita às rotinas de produção que também orientam essa atividade profissional. Uma sólida tradição de pesquisa em jornalismo busca compreender como determinados fatos são transformados em notícia: a constatação dos valores notícia (CAPLE; BEDNAREK, 2016) e a estrutura das redações. Não há, porém, investigação no campo novo dos agentes de checagem, o que torna necessário investigar como eles se comportam para escolher quais políticos retratar.

Os dados existentes na pesquisa brasileira sobre checagem (ALENCAR; DOURADO, 2020; FERRACIOLI; SBARAINI FONTES, 2019), porém, são provenientes apenas da análise das matérias publicadas. Uma visão mais ampla que conectasse a percepção dos jornalistas com o resultado das checagens poderia se mostrar benéfica. Em razão disso, foi formulado o problema de pesquisa que guiou esse trabalho: há coerência entre a visão dos jornalistas sobre a escolha dos checados ao longo da produção e a recorrência de checagens postadas ao longo da cobertura?

Como objeto empírico que pudesse retratar a relação que se quer analisar, foi escolhido o projeto Comprova, iniciativa brasileira de colaboração entre diversos meios de comunicação de regiões distintas. A atuação desses jornalistas ao longo da eleição de 2018 pode apontar de que maneira o jornalismo de checagem se relacionou com o campo político diretamente envolvido no pleito presidencial. 
O artigo está dividido conforme a seguinte estrutura: a seguir será apresentado uma breve revisão de literatura sobre a checagem de fatos, em especial na sua relação com o campo político. Em seguida será feita uma descrição.

\section{JORNALISMO DE CHECAGEM DE FATOS}

Na concepção norte-americana, páis onde foi primeiro estabelecido, a checagem consiste em “determinar a veracidade de afirmações políticas públicas” (GRAVES, 2018, p. 3). É importante destacar que a checagem aqui mencionada não se confunde com o ato de checar as informações que é típico do processo de apuração jornalística: a checagem de fatos se tornou um produto jornalístico em si, ofertado ao público de maneira isolada. A primeira empreitada de checar falas e divulgar ao público surgiu ainda na década de 90 nos Estados Unidos, quando trechos de propagandas políticas de candidatos foram apontados como verdadeiros ou falsos. Na Europa, a primeira iniciativa surgiu no Reino Unido, quando a BBC começou a divulgar checagens ao longo da campanha para as eleições parlamentares de 2005 (KUŚ; BARCZYSZYN-MADZIARZ, 2020). É somente a partir da década de 2010 que essas iniciativas se espalham ao redor do mundo e superam a marca de 100 agentes já em 2016 (GRAVES, 2018).

Foi também no país americano que se estabeleceu uma divisão clara entre os checadores jornalistas e aqueles envolvidos com campanhas políticas e organizações partidárias. É o caso do Media Research Center, grupo conservador que monitora a mídia, e o Media Matters, organização ligada ao Partido Democrata norte-americano que também faz checagens de conteúdos. Os grupos jornalísticos de checagem, contudo, buscam estabelecer uma fronteira entre eles e os 'checadores partidários', evitando citar seu trabalho ou até mesmo participar dos eventos (GRAVES, 2018).

Apesar de buscar manter distanciamento de organizações ligadas diretamente ao campo político, os checadores dos EUA sempre mantiveram proximidade com o campo acadêmico e organizações da sociedade civil. O veículo estadunidense com mais seguidores no Twitter e no Facebook, o Factcheck.org, é mantido por um centro de estudos de políticas públicas da Universidade da Pensilvânia, o que ressalta essa tendência, percebida também em outros países, como Polônia e Republica Tcheca (GIEREŁO-KLIMASZEWSKA, 2019; KUŚ; BARCZYSZYNMADZIARZ, 2020).

A checagem pode assumir, ademais, uma função educativa, ao permitir que a população distinga o que é verdadeiro do que é manipulação no espaço público. Na Polônia, foi percebido que 
algumas agências de checagem consideram esse propósito educacional como sua prioridade (KUS). A intenção desses agentes está diretamente conectada com o empenho em fomentar o espírito crítico nos leitores para que eles mesmos saibam encontrar maneiras de identificar falsidades com que se deparem por meio das redes sociais (GIEREŁO-KLIMASZEWSKA, 2019). Esse propósito, contudo, é rejeitado por muitos checadores norte-americanos que rejeitam a ideia de que a checagem pode contribuir para o discurso público, pois a função de um jornalista e, portanto, de um checador seria apenas prover informações, e não alterar o comportamento político dos cidadãos (GRAVES, 2018).

Nota-se, dessa maneira, que existe uma relação muito íntima entre o campo político e a atuação dos checadores, que não se restringe à cobertura realizada, mas também ao modo de constituição desses agentes. Eles possuem financiamento não tão dependente de publicidade, mas sim dos próprios leitores; privilegiam eventos como discursos e pronunciamentos em vez de desastres ou fatos chamativos; possui uma meta persuasiva, de convencer o leitor de que a conclusão da checagem está correta, o que implica na ampla transparência das fontes adotadas (SEIBT, 2019).

A pesquisa acadêmica tem se dedicado sobretudo a constatar as possíveis influências das checagens nas opiniões e comportamentos dos cidadãos. Já se descobriu, assim, que aqueles leitores que foram primeiro apresentados a uma informação falsa e depois leram a checagem disso tenderam a repudiar o conteúdo falso mais do que aqueles que não tiveram acesso, como apontaram Garret, Nisbert e Lynch (2013).

\section{FACT-CHECKING NO BRASIL E O CASO DO PROJETO COMPROVA}

No Brasil, a primeira iniciativa de checagem data de 2010, quando o jornal Folha de S. Paulo lançou uma seção Mentirômetro em que apontavam dados incorretos nas declarações dos postulantes das eleições daquele ano; tal fenômeno se repetiu na eleição de 2014, quando os jornais O Globo e o projeto Truco também lançaram iniciativas. Já em 2015 o Brasil contava com suas duas primeiras agências de checagem fixas e dedicadas exclusivamente à prática: Aos Fatos e Lupa. Ambas continuam em atividade e possuem destaque no campo jornalístico.

Dentre as iniciativas existentes, esse artigo optou por analisar o projeto Comprova, fundado em 2018 com apoio da Abraji (Associação Brasileira de Jornalismo Investigativo), bem como do Google e do Facebook. Trata-se de uma ideia colaborativa, em que 24 meios de comunicação das 
mais distintas plataformas (rádio, televisão, jornal impresso, Internet) cediam colaboradores para que trabalhassem em conjunto para checar fatos relacionados às eleições presidenciais daquele ano. No ano de 2020 o projeto continua em atuação, com foco à desinformação que circula e com número ampliado de 28 meios integrantes, passando a ter representantes de todas as regiões do Brasil.

O desenvolvimento da checagem no Brasil levou à aparição de estudos recentes que buscaram investigar a atuação dos checadores de fatos no país. Enquanto Becker (2019) demonstrou como a prática evoluiu entre os repórteres brasileiros, Seibt (2019) optou por categorizar o fenômeno sob a alcunha de jornalismo de verificação, construindo categorias que o distinguem do jornalismo tradicional. Alencar e Dourado (2020) se voltaram para as checagens feitas por Folha de S. Paulo e O Estado de S. Paulo no segundo turno das eleições presidenciais de 2018, tendo concluído que essa ação foi uma maneira de manter a credibilidade dos veículos, ainda que cada um dos meios tenha apresentado diferenças ao reportar. Até mesmo na área da ciência da informação já existe investigação que se propõe a demonstrar como as checagens lidam com o acesso e o excesso de informação.

Uma comparação entre o conteúdo das checagens e a percepção dos checadores sobre seu labor, contudo, ainda não foi produzida, o que levou ao desenho de pesquisa a ser esmiuçado a seguir.

\section{ESCOLHAS METODOLÓGICAS E ANÁLISE}

Para atingir o objetivo proposto nesse artigo, o desenho de pesquisa se debruçou sobre dois aspectos: o conteúdo publicado e as percepções dos jornalistas.

A estratégia adequada para lidar com os artigos foi a análise de conteúdo (BARDIN, 2011; BAUER, 2002). Para isso, dois codificadores foram responsáveis por classificar os textos postados pelo site entre agosto e outubro de 2018, que corresponde ao período eleitoral naquele ano.

O corpus analisado, assim, consistiu nas 145 checagens publicadas pelo projeto Comprova ao longo desse intervalo de tempo. A primeira informação que foi verificada consistiu em saber qual candidato tinha sido citado em cada um dos textos, o que pode ser visto na tabela 1 abaixo. $\mathrm{O}$ mais mencionado foi Jair Bolsonaro (então no PSL), seguido por Fernando Haddad e Lula, que teve a candidatura rejeitada pelo TSE. 
TABELA 1 - CANDIDATOS MENCIONADOS NO CONTEÚDO CHECADO

\begin{tabular}{|c|c|c|c|}
\hline & Cargo a que concorreu & $\mathbf{N}$ & $\%$ \\
\hline Jair Bolsonaro (PSL) & Presidente & 63 & 43,4 \\
\hline Fernando Haddad (PT) & Presidente & 34 & 23,4 \\
\hline Lula (PT) & Presidente & 26 & 17,9 \\
\hline Geraldo Alckmin (PSDB) & Presidente & 7 & 4,8 \\
\hline Dilma Rousseff (PT) & Senadora & 6 & 4,1 \\
\hline Ciro Gomes (PDT) & Presidente & 5 & 3,4 \\
\hline Gleisi Hoffmann (PT) & Deputada federal & 5 & 3,4 \\
\hline Jean Wyllys (PSOL) & Deputado federal & 3 & 2,1 \\
\hline João Amoêdo (Novo) & Presidente & 2 & 1,4 \\
\hline Manuela D'Ávila (PC do B) & Vice-presidente & 2 & 1,4 \\
\hline Marina Silva (Rede) & Presidente & 2 & 1,4 \\
\hline Tenente Zucco (PSL) & Deputado estadual & 2 & 1,4 \\
\hline Cabo Daciolo (Patriota) & Presidente & 1 & 0,7 \\
\hline Delegado Francischini (PSL) & Deputado estadual & 1 & 0,7 \\
\hline Sônia Guajajara (PSOL) & Vice-presidente & 1 & 0,7 \\
\hline Christian Lohbauer (Novo) & Vice-presidente & 1 & 0,7 \\
\hline Lindbergh Farias (PT) & Senador & 1 & 0,7 \\
\hline
\end{tabular}

FONTE: O AUTOR (2020)

Além de identificar os candidatos mencionados, a análise verificou também se os conteúdos checados eram positivos, negativos ou neutros em relação a eles. Para ilustrar essa divisão, é possível mostrar situações hipotéticas: uma notícia era positiva quando afirmava que um candidato $\mathrm{X}$ nunca havia sido condenado por corrupção; ela foi classificada como negativa quando trazia algum fato desabonador do concorrente; exemplo: candidato $\mathrm{Z}$ recebeu salário público sem trabalhar. Do total de menções a candidatos (162), a maioria delas eram negativas em relação aos concorrentes (101 casos - 62,3\%), enquanto apenas 25\% diziam respeito a conteúdos positivos (42 ocorrências). As outras 19 menções eram neutras $(11,7 \%)$ em relação aos candidatos. $\mathrm{O}$ total de menções não é igual ao número de textos porque alguns textos mencionavam mais de um candidato.

A tabela abaixo apresenta uma divisão por candidato da valência da notícia ou afirmação que foi desvendada, limitada aos sete candidatos mais frequentes. 
TABELA 2 - VALÊNCIA EM RELAÇÃO AOS CANDIDATOS CITADOS NOS CONTEÚDOS CHECADOS

\begin{tabular}{|c|c|c|c|c|c|}
\hline \multicolumn{2}{|l|}{ Candidato } & Positivo & Negativo & Neutro & Total \\
\hline \multirow[b]{2}{*}{ Jair Bolsonaro (PSL) } & $\mathbf{N}$ & 34 & 16 & 13 & 63 \\
\hline & $\%$ & 54 & 25,4 & 20,6 & 100 \\
\hline \multirow[b]{2}{*}{ Fernando Haddad (PT) } & $\mathbf{N}$ & 3 & 30 & 1 & 34 \\
\hline & $\%$ & 8,8 & 88,2 & 2,9 & 100 \\
\hline \multirow[b]{2}{*}{ Lula (PT) } & $\mathbf{N}$ & 4 & 20 & 2 & 26 \\
\hline & $\%$ & 15,4 & 76,9 & 7,7 & 100 \\
\hline \multirow[b]{2}{*}{ Outros candidatos } & $\mathbf{N}$ & 1 & 14 & 1 & 16 \\
\hline & $\%$ & 6,25 & 87,5 & 6,25 & 100 \\
\hline \multirow[b]{2}{*}{ Geraldo Alckmin (PSDB) } & $\mathbf{N}$ & 0 & 6 & 1 & 7 \\
\hline & $\%$ & 0 & 85,7 & 14,3 & 100 \\
\hline \multirow[b]{2}{*}{ Dilma Rousseff (PT) } & $\mathbf{N}$ & 0 & 6 & 0 & 6 \\
\hline & $\%$ & 0 & 100 & 0 & 100 \\
\hline \multirow[b]{2}{*}{ Ciro Gomes (PDT) } & $\mathbf{N}$ & 0 & 4 & 1 & 5 \\
\hline & $\%$ & 0 & 80 & 20 & 100 \\
\hline \multirow[b]{2}{*}{ Gleisi Hoffmann (PT) } & $\mathbf{N}$ & 0 & 5 & 0 & 5 \\
\hline & $\%$ & 0 & 100 & 0 & 100 \\
\hline
\end{tabular}

Em relação à outra estratégia, levou-se em conta que o conjunto de sujeitos pesquisados era reduzido, o que indica a entrevista como melhor técnica de coleta de material (HALPERIN; HEATH, 2017). Quatro jornalistas aceitaram participar, cientes de que os dados seriam tratados de maneira anônima.

A opção foi por conduzir entrevistas do tipo semi-estruturadas a partir de um roteiro prévio de perguntas. Assim, era possível que o entrevistado discorresse sobre os assuntos, sem que houvesse uma rigidez excessiva (BONI; QUARESMA, 2005). Esse tipo de entrevista é recomendado quando o pesquisador já tem hipóteses e questões de pesquisa formulados, pois sua condução permitirá que os entrevistados não desviem dos assuntos que interessam à investigação (LEECH, 2002). As entrevistas foram realizadas por Skype, uma vez que os participantes habitavam em cidades diferentes, pois trabalhavam originalmente em meios de comunicação distintos, como já mencionado na seção anterior. 
Em relação ao objetivo dessa investigação, foi perguntado especificamente aos checadores se a cobertura de que participaram tinham alvo preferencial ou se focava em candidatos específicos. Abaixo seguem as respostas, dos entrevistados A, B, C e D:

ENTREVISTADO A - Eu não diria uma preferência. Mas o volume de desinformações de um lado era muito maior do que do outro. Chegava muito mais pra gente. Não é uma preferência. Chegou uma fakenews do Amoedo para desmentir, "do Amoedo não vou fazer porque eu não gosto dele". Não, porque todo mundo tinha que estar fazendo coisas, a gente tinha que fazer o que chegasse no dia. Quanto mais a gente fizesse, melhor para o projeto. Então você não escolhia muito. Mas a quantidade de informações negativas em relação ao PT e positivas em relação ao Bolsonaro eram do mesmo tamanho e elas ocupavam quase todo o trabalho que a gente fazia. O que não quer dizer, necessariamente, que o pessoal do Bolsonaro fazia mais fakenews que o pessoal do PT. O que eu acho que acontecia mais é que as fakenews relacionadas ao Bolsonaro, feitas por ele ou não, por pessoas que apoiam ele ou não, elas eram muito mais eficientes. Atingiam mais pessoas. Esse era o primeiro critério da gente, o que circulava mais. Podia ser que todo mundo fizesse a mesma quantidade de fakenews, todos os candidatos. Só que as relacionadas ao Bolsonaro viralizaram muito mais, seja por ele próprio, por algum filho publicar ou algum apoiador dele, tipo o Magno Malta ou o Alexandre Frota, porque essas pessoas tinham muita visibilidade e alcance. Se um cara desses retweetava uma fakenews qualquer negativa em relação ao PT ou positiva em relação ao Bolsonaro, isso se espalhava muito mais do que qualquer outra.

ENTREVISTADO B - Não, de maneira alguma, não senti nenhum viés nesse sentido. Pelo contrário, a gente fez checagens relacionadas à maioria dos candidatos, foram vários, claro que Jair Bolsonaro e Fernando Haddad foram os principais, eles eram os que foram para o segundo turno, mas fizemos de todos os candidatos. Candidatos que tinham $1 \%$ dos votos, $5 \%$ dos votos, todos esses passaram por checagens. Com certeza as checagens realizadas ao candidato Jair Bolsonaro serão em maior quantidade, porque o fato é que a maneira como ele fazia campanha era pelas redes sociais, ele e os apoiadores dele movimentam as redes sociais de maneira muito mais intensa que os outros. Isso não é novidade, consequentemente, o volume de notícias falsas e o alcance de coisas falsas que alguns apoiadores compartilhavam era muito maior e isso aparecia no nosso radar em maior quantidade também.

ENTREVISTADO C - Não, esse foi um problema. Era uma coisa que a gente discutia porque a gente tentava checar a mesma quantidade de coisas de todos os candidatos. Então procurava equilibrar. Fiz uma checagem sobre o Bolsonaro, então quero fazer uma checagem sobre o Ciro, quero fazer uma checagem sobre o Haddad ou a Mari. Tentava achar uma coisa de cada candidato. Só que era muita a oferta. Era uma questão também do processo do Comprova, que o objetivo do programa não era dar mais fôlego para um boato do que ele teria. Então a gente um desafio a mais na seleção do boato que era se for uma coisa muito pequena talvez não valha a checagem porque você amplifica a mentira mostrando a verdade. Então tinha essa questão do que escolher. Só que durante a campanha, tinha muito mais material, principalmente envolvendo o Bolsonaro, ele aparecia em muito mais quantidade do que os outros candidatos. Então as vezes você conseguia caçar uma coisa que estava repercutindo de um candidato, mas a oferta não era igual para todos. Era uma questão que a gente tentava equilibrar para fazer alguma coisa com todos, mas nem sempre esse equilíbrio era possível mais pela questão da oferta porque não é como se a gente estivesse caçando só um candidato, mas para cumprir os critérios do projeto, as vezes tinha essa discrepância de aparecer muito mais de um candidato do que do outro. Então, por exemplo, o Amoedo a gente fez uma ou duas checagens sobre ele, o Bolsonaro era o que mais tinha com certeza.

ENTREVISTADO D - Sim. Não é um viés da verdade. Eu acho que é o volume de informação. É o volume de informação que acaba chegando. Você via muita coisa mais do Haddad e do Bolsonaro do que dos outros candidatos. Já percebia que a eleição estava polarizada. Chegavam informação que desmentiam, que eram para atingir o Bolsonaro e informações que eram para atingir o Haddad. Até o Ciro. Na escalabilidade, você tinha maior volume de informações pró- 
Bolsonaro que criava uma mentira pro PT e o PT tinha alguma coisa também. Era o segundo volume de informações nesse sentido que tinha mentiras que tentavam enviesar para o Bolsonaro. Só que o volume era bem menor do que o do Bolsonaro. Ciro então ficava bem mais na retaguarda. Ciro, Marina, Alckmin então mais longe ainda. Com isso você percebe que realmente a campanha eleitoral do pesselista, a rede social, a internet teve um peso forte. $O$ pessoal que era mais da rede do Bolsonaro era um pessoal muito mais engajado. Eles conseguiam fazer o que a parte da esquerda não fez. O que a esquerda consegue engajar as pessoas para as ruas, nesse sentido de manifestações ou algo do tipo, a direita fez isso muito bem, direita ou oposição ao PT, fez isso muito bem nas redes sociais. Eles conseguiram fazer uma corrida muito bem integrada e distribuída. Então foi um trabalho primoroso se você olhar o que foi feito. E até explica o porquê desse governo que está aí agora.

Uma vez apresentados os resultados da análise das checagens e das entrevistas realizadas, é possível debater a questão que norteou esse artigo, o que será discutido na seção a seguir.

\section{DISCUSSÃO DOS RESULTADOS}

Como já apontado por Alencar e Dourado (2020), o fact-checking é um recurso utilizado para que os meios de comunicação reforcem sua legitimidade. Nesse sentido, a pesquisa realizada apontou que a verificação de conteúdos pelo projeto Comprova foi uma maneira de tornar o jornalismo útil ao longo da campanha eleitoral de 2020.

Os números demonstram que os dois candidatos que chegaram ao segundo turno foram os mais mencionados, o que indica que a checagem não foi produzida alheia à disputa: produzir mais conteúdos sobre candidatos com porcentagens baixas de conteúdo poderia render textos anedóticos mas não dialogaria com a maior parte do eleitorado brasileiro. Essa pode indicar uma maneira de como o projeto Comprova construiu sua credibilidade, oferecendo checagens sobre candidatos relevantes, o que poderia contribuir para mudanças nas preferências dos eleitores que afetassem a disputa.

A fala de entrevistado A em que ele menciona sua rotina indica um aspecto importante da profissionalização da checagem, que consiste no ideal de objetividade: "chegou uma fakenews do Amoedo para desmentir, 'do Amoedo não vou fazer porque eu não gosto dele'. Não, porque todo mundo tinha que estar fazendo coisas, a gente tinha que fazer o que chegasse no dia". O trecho revela como, na visão dos checadores, a escolha dos retratados é decorrência apenas de uma atuação jornalística, que deve-se guiar por valores que regem o jornalismo. Não haveria como recusar a feitura de checagem sobre um candidato particular, porque o valor da objetividade se sobreporia à preferência pessoal do checador. A checagem seria, assim, um dos métodos de se praticar jornalismo (GRAVES, 2018). 
Isso é um aspecto importante da lógica jornalística que é abraçado pelos checadores: o discurso de autonomia do agente de checagem dos interesses políticos e econômicos, que foi fundamental para estabelecimento do jornalismo como atividade econômica sustentável (SCHUDSON, 2001). Assim menciona o candidato C, que afirma que "a gente discutia porque a gente tentava checar a mesma quantidade de coisas de todos os candidatos. Então procurava equilibrar. Fiz uma checagem sobre o Bolsonaro, então quero fazer uma checagem sobre o Ciro, quero fazer uma checagem sobre o Haddad ou a Marina." Nítida está nesse trecho a ideia de equilíbrio e neutralidade que o checador pretende buscar.

Isso se constata quando o candidato B afirma que "candidatos que tinham 1\% dos votos, $5 \%$ dos votos, todos esses passaram por checagens", evidenciando o próposito de equilíbrio na cobertura. A análise de conteúdo demonstrou que candidatos que tiveram baixa quantidade de votos como Cabo Daciolo e Marina Silva foram checados pelo projeto. Entretanto, candidatos melhores posicionados como Henrique Meirelles não foram alvo de cobertura do Comprova ao longo de toda a campanha. O discurso dos jornalistas sobre suas práticas não foi capaz, porém, de apontar motivos para a ausência desse concorrente.

É possível perceber também como os checadores construíram critérios de noticiabilidade, tais como a literatura tradicionalmente aponta (HARCUP; O'NEILL, 2001, 2017). O jornalista A responde que a prevalência de conteúdo sobre Jair Bolsonaro decorre do fato de que "atingiam mais pessoas. Esse era o primeiro critério da gente, o que circulava mais. Podia ser que todo mundo fizesse a mesma quantidade de fakenews, todos os candidatos. Só que as relacionadas ao Bolsonaro viralizaram muito mais". Nota-se como o critério do alcance do conteúdo falso motivou a escolha dos conteúdos e acabou resultando no predomínio do candidato que viria a ser eleito.

Os checadores, em seus relatos sobre os alvos da cobertura, apontaram que sentiam diferença na maneira de circulação dos conteúdos do presidente Bolsonaro. Foram nessa linha os depoimentos de A "as relacionadas ao Bolsonaro viralizaram muito mais, seja por ele próprio, por algum filho publicar ou algum apoiador dele, tipo o Magno Malta ou o Alexandre Frota, porque essas pessoas tinham muita visibilidade e alcance. Se um cara desses retweetava uma fake news qualquer negativa em relação ao PT ou positiva em relação ao Bolsonaro, isso se espalhava muito mais do que qualquer outra", de B: "Com certeza as checagens realizadas ao candidato Jair Bolsonaro serão em maior quantidade, porque o fato é que a maneira como ele fazia campanha era pelas redes sociais, ele e os apoiadores dele movimentam as redes sociais de maneira muito mais 
intensa que os outros" e D "você tinha maior volume de informações pró-Bolsonaro que criava uma mentira pro PT e o PT tinha alguma coisa também”.

Essa linha de relatos demonstra que os jornalistas perceberam um modo de atuação da campanha de Bolsonaro que estava muito conectado com a disseminação de conteúdo pelas mídias digitais. Por mais que uma confirmação sobre esse papel dependa de pesquisas direcionadas ao estudo da atuação das campanhas dos candidatos, as entrevistas puderam demonstrar que os jornalistas se concentraram em desvendar conteúdo que estava relacionado à campanha do Bolsonaro e se justificam por meio do maior alcance.

A análise realizada demonstrou que os conteúdos relativos a Bolsonaro eram, em regra, positivos a ele e os que citavam Haddad eram majoritariamente negativos ao petista. Nesse ponto, há uma confluência entre o conteúdo publicado pelo Comprova e a descrição dos profissionais sobre sua atuação: afirmações falsas ligadas à campanha do então deputado federal receberam mais atenção seja por se tratar de conteúdos que eram favoráveis a ele ou desfavoráveis a seu adversário, porém não correspondiam à realidade.

\section{CONSIDERAÇÕES FINAIS}

A circulação em massa de informações pelas redes sociais digitais tornou mais relevante o debate sobre suas implicâncias para o contexto político. Se em 2016 a eleição de Donald Trump teve apontada como uma das causas o uso de dados obtidos pela empresa Cambridge Analytica, as novas eleições passam a ocorrer sempre sob o perigo de que informações inverídicas possam influenciar o voto dos eleitores. A atuação dos agentes de fact-checking parece acompanhar a produção desses conteúdos de origem duvidosa.

As entrevistas conduzidas nessa pesquisa mostraram como a checagem de fatos é uma maneira de perpetuar a lógica jornalística e as características que lhe são tradicionais: a objetividade, a concessão de espaço para todos os lados envolvidos, entre outras características (TUCHMAN, 1972). Ademais, a percepção dos profissionais sobre suas rotinas de produção os levou a perceber que o critério adotado para escolher quais assuntos checar os levou a centralizar em alguns candidatos. Essa opção por se centrar em conteúdos mais divulgados ou compartilhados nas redes acarretou com que os dois participantes do segundo turno já dominassem as checagens desde o início, o que foi constatado tanto na análise de conteúdo dos posts quanto nos depoimentos tomados dos profissionais envolvidos. 
Reconhece-se que no presente caso houve um olhar concentrado para uma situação específica, de modo que generalizações não devem ser feitas sem critérios. Pesquisas futuras, assim, podem aprofundar tais achados de diferentes maneiras: é possível olhar para empresas de checagem com empregados estáveis (em oposição aos colaboradores provenientes de meios diferentes que caracterizam o Comprova), fazer comparações entre checagens de alvos regionais e nacionais, para perceber se a proximidade ao político citado influencia a produção de conteúdo. O uso de outras técnicas de coleta de dados, como o questionário, pode ser útil ao ampliar o acesso aos profissionais, o que facilita uma compreensão maior do objeto.

Pesquisas futuras também podem avaliar com mais precisão a construção do discurso de checagem como produto jornalístico relevante, averiguando de que maneira esse gênero vem se consolidando como resposta dos meios de comunicação à onda de desinformação. Os achados aqui presentes revelam pista que podem ser melhor exploradas em pesquisas voltadas para esse objetivo.

Como o Brasil é um país que sofre profundas influências do jornalismo norte-americano e as adaptou conforme as características locais, seria interessante, ainda, averiguar como outras nações, com sistemas midiáticos antagônicos, acolheram a prática de checagem de fatos e como eles se comportam perante seus alvos do campo político. Os achados dessa investigação são fruto de um sistema parlamentarista, mas as campanhas eleitorais em nações parlamentaristas estão sujeitas a outras relações entre candidatos e meios de comunicação, o que demanda estudos que as abranjam. Além disso, a distinção entre lista fechada e lista aberta, por exemplo, pode ter impacto em como ocorre a cobertura dos candidatos, já que mesmo o desapreço por um dos candidatos do partido não precisa levar o eleitor a abandonar a sigla que apoia.

\section{REFERENCIAS}

ALENCAR, M. T.; DOURADO, J. L. Fact-checking : checagens da Folha e do Estadão na construção da credibilidade jornalística na internet. Revista Eletrônica Internacional de Economia Política da Informação, da Comunicação e da Cultura, v. 22, n. 2, p. 23-37, 2020.

BARDIN, L. Análise de conteúdo. São Paulo: Edições 70, 2011.

BAUER, M. Análise de conteúdo clássica: uma revisão. In: Pesquisa qualitativa com texto, imagem e som: um manual prático. Rio de Janeiro: Vozes, 2002. p. 189-217.

BECKER, D. A evolução do fact-checking como atividade jornalística no brasil: lacunas e tendências. Comunicação: Reflexões, experiências, ensino, v. 15, n. 1, 2019. 
BONI, V.; QUARESMA, S. J. Aprendendo a entrevistar: como fazer entrevistas em Ciências Sociais. Em Tese, v. 2, n. 1, p. 68-80, 2005.

CAPLE, H.; BEDNAREK, M. Rethinking news values: What a discursive approach can tell us about the construction of news discourse and news photography. Journalism: Theory, Practice \& Criticism, v. 17, n. 4, p. 435-455, 2 maio 2016.

FERRACIOLI, P.; SBARAINI FONTES, G. A reação do Jornalismo às fake news: uma análise das checagens realizadas pelo projeto Comprova ao longo da campanha eleitoral de 2018. In: O Brasil vai às urnas: as campanhas eleitorais para presidente na TV e internet. Londrina-PR: Syntagma, 2019.

GARRETT, R. K.; NISBET, E. C.; LYNCH, E. K. Undermining the Corrective Effects of MediaBased Political Fact Checking? The Role of Contextual Cues and Naïve Theory. Journal of Communication, v. 63, n. 4, p. 617-637, ago. 2013.

GIEREŁO-KLIMASZEWSKA, K. Political Fact-checking in the Czech Republic on the Example of demagog.cz and manipulatori.cz Portals. Mediatization Studies, v. 3, p. 115-135, 16 out. 2019.

GRAVES, L. Boundaries Not Drawn: Mapping the institutional roots of the global fact-checking movement. Journalism Studies, v. 19, n. 5, p. 613-631, 4 abr. 2018.

HALPERIN, S.; HEATH, O. Interviewing and Focus Groups. In: Political Research: Methods and Practical Skills. [s.1.] Oxford University Press, 2017. v. 1.

HARCUP, T.; O’NEILL, D. What Is News? Galtung and Ruge revisited. Journalism Studies, v. 2, n. 2, p. 261-280, jan. 2001.

HARCUP, T.; O'NEILL, D. What is News?: News values revisited (again). Journalism Studies, v. 18, n. 12, p. 1470-1488, dez. 2017.

KUŚ, M.; BARCZYSZYN-MADZIARZ, P. Fact-checking initiatives as promoters of media and information literacy: The case of Poland. Central European Journal of Communication, v. 13, n. 2, p. 249-265, 2020.

LEECH, B. L. Asking Questions: Techniques for Semistructured Interviews. PS: Political Science and Politics, v. 35, n. 4, p. 665-668, 2002.

MENG, R.; JUN, Y.; JOHAR, G. Research: Being in a Group Makes Us Less Likely to Fact-Check. Harvard Business Review, 2017.

SCHUDSON, M. The objectivity norm in American journalism. Journalism, v. 2, n. 2, p. 149-170, ago. 2001.

SEIBT, T. Jornalismo de verificação como tipo ideal: a prática de fact-checking no Brasil. Porto Alegre-RS: [s.n.]. 
TUCHMAN, G. Objectivity as Strategic Ritual: An Examination of Newsmen's Notions of Objectivity. American Journal of Sociology, v. 77, n. 4, p. 660-679, jan. 1972. 